\title{
PROJETO EXPOSIÇÕES ITINERANTES: A INTERDISCIPLINARIDADE E A INOVAÇÃO NO ENSINO DE DESIGN
}

Délcio Julião Emar de Almeida

Centro Universitário de Belo Horizonte - UNIBH

delcio.almeida@prof.unibh.br

Rangel Benedito Sales de Almeida

Centro Universitário de Belo Horizonte - UNIBH

rangel.almeida@prof.unibh.br

Resumo: O projeto Exposições Itinerantes surge a partir das demandas curriculares dos Trabalhos Interdisciplinares de Graduação (TIG), direcionados aos cursos de Tecnólogo em Design Gráfico desenvolvidos no Centro Universitário de Belo Horizonte - UNIBH. Refere-se ao desenvolvimento um projeto de programação visual e maquetaria, o qual engloba os conteúdos de Sinalética e Design Corporativo, Acabamento e Design de Embalagens, Insumos Gráficos e Sistemas de Impressão, PréImpressão e fechamento de arquivos ao passo que todos esses conteúdos são abordados massivamente na produção e no planejamento de uma exposição itinerante. Nesse sentido, o projeto contou com uma série de estratégias para que as atividades práticas de cada uma das disciplinas contribuíssem com o TIG durante todo seu processo de planejamento, execução e apresentação. Objetiva, portanto, buscar a integração teoriaprática mediante o exercício da observação e análise, na busca de um processo de ensino-aprendizagem pautado na pesquisa e na prática do campo de atuação do designer. Dessa forma, trabalhando a relação interdisciplinar entre os conteúdos, congrega talentos, fomenta a postura cooperativa em detrimento à competitiva, estimula finalidades comunicativas e de informação, no sentido de um resultado transdisciplinar.

Palavras-chave: ensino de design, interdisciplinaridade, inovação, exposições, maquetaria.

Abstract: The Project Itinerant Exhibition comes from the curricular demands of Graduate Interdisciplinary Works (TIG), directed to Technologist courses in Graphic Design developed at the University Center of Belo Horizonte - UNIBH. Refers to developing a visual programming project and mockups, which encompasses Signage content and Corporate Design, Finishing and Packaging Design, Graphics Supplies and Printing Systems, Prepress and Closing Files while all this content they are covered heavily in production and planning a traveling exhibition. In this sense, the 
project had a number of strategies for the practical activities of each of the disciplines contribute to the TIG throughout their planning, execution and presentation. Objective, therefore, seek the theory-practice integration through the exercise of observation and analysis, in search of a guided teaching-learning process in the research and practice of the designer playing field. Thus, interdisciplinary working relationship between the contents, brings talent, promotes cooperative position, rather than the competitive stimulates communication and information purposes, towards a transdisciplinarity.

keywords: design education, interdisciplinarity, innovation, exhibitions, mockup.

\section{INTRODUÇÃO}

O projeto, intitulado inicialmente como Exposições Itinerantes - O Designer Gráfico e o Planejamento Visual de Espaços Culturais, foi desenvolvido para contemplar as ementas do Módulo III do curso de Tecnólogo em Design Gráfico do Centro Universitário de Belo Horizonte - UNIBH, fazendo parte da disciplina Trabalhos Interdisciplinar de Graduação (TIG). A disciplina TIG foi implanta pela Instituição no sentido de propor uma reestruturação curricular que promovesse a interdisciplinaridade dentro e fora de aula (UNIBH, 2015). Chancelada pela Resolução CEPE No 01/2009, a disciplina TIG se baseia organização de projetos que corroboram nas formas sistemáticas, organizadas e solidárias entre os discentes e docentes, ampliando os espaços de aprendizagem e possibilitando uma formação acadêmica autônoma, social e intelectualmente pautada. Faz-se importante enfatizar que tal disciplina faz para do currículo de todos os cursos dos Institutos que compõem a estrutura do UNIBH.

Dessa forma, todos os alunos matriculados na disciplina TIG devem desenvolver um projeto com viés interdisciplinar, envolvendo pesquisa acadêmica e desenvolvimento de projeto, sob a orientação de um professor mediador e dos professores das demais disciplinas dos respectivos módulos, sustentados e orientados por edital específico, ajustado para o projeto proposto, e pelos planos de ensino de cada disciplina. Tais projetos não podem ser desenvolvidos individualmente, já que o objetivo do mesmo é a inter-relação e o exercício da interdependência entre os componentes, que se envolvem nas dinâmicas intensas de trocas e afetos, cabendo aos mesmos a responsabilidade pela manutenção de uma equipe solidária, ética e responsável.

Os temas dos projetos dependerão das disciplinas que são ministradas nos módulos específicos e são discutidas anteriormente pelo corpo docente junto com a coordenação. Esse tema se porta como um eixo principal que orientará todas as diretrizes do projeto, mas as equipes possuem a autonomia de propor subtemas, os quais devem se adequar ao tema principal. Quanto aos produtos, esses são igualmente pré-definidos pela equipe de professores, no sentido de contemplar todas as disciplinas envolvidas. Na etapa da Metodologia, será apresentado, de forma mais detalhada, o percurso de sistematização que levou ao surgimento do Projeto Exposições Itinerantes para o Módulo III do Design Gráfico. 
Dessa forma, o artigo abordará questões teóricas relacionadas à inter e transdisciplinaridade, base teórica que orienta o presente projeto e guiará na busca do entendimento do que sejam tais termos, pois se verificam ainda muitos equívocos relacionados aos mesmos.

\section{DESENVOLVIMENTO}

Na presente seção, será apresentada uma breve revisão da literatura no que concerne aos termos disciplinaridade, interdisciplinaridade e transdisciplinaridade, objetivando entender o porquê da urgência de projetos com foco na colaboração e propostas sistêmicas e sinérgicas, essenciais para a construção do perfil do egresso dos cursos de design, embasado em competências, habilidades e uma visão de mundo mais ampla e autônoma.

\subsection{Interdisciplinaridade e Transdisciplinaridade}

O mundo contemporâneo se apresenta para os agentes sociais como um desafio novo a cada dia, já que as mudanças tecnológicas impactam sobremaneira nas questões comunicações e de consumo, além de contarem com sujeitos críticos e ativos nas dinâmicas da construção do social. Rancière (2005) argumenta que existe uma partilha do comum, sendo esse comum composto por toda a produção cultural humana, na qual são compartilhados códigos, pensamentos, referências e comportamentos. O indivíduo, participante ativo do contexto social, exerce papeis que refletem na estrutura desse todo compartilhado. O autor propõe que esse "sensível" é aquilo que se apresenta ao indivíduo, disponível a esse para que seja percebido, codificado e recodificado, transformado e ampliado os discursos e as visibilidades, no corpo complexo das relações éticas, representacionais e estéticas (RANCIÈRE, 2005).

Isto posto, não é possível hoje enxergar e tratar da mesma forma tradicional, os envolvidos nas dinâmicas de ensino e aprendizagem. Não há mais espaço para relações verticalizadas, nas quais os alunos são apenas receptores do conhecimento rotineiro e pragmático, transmitido por um professor hierarquizado e burocrático. Portanto, verifica-se a necessidade constante de se inventar e reinventar o cotidiano, abrindo e repensando novas possibilidades e paradigmas. Essas reflexões apontam para, segundo Fontoura (2011), uma superação de formas tradicionais de pensamento, enquadradas nos domínios da disciplinaridade.

Os estudos a respeito dos processos dos processos de ensino/aprendizagem na busca da construção do conhecimento encontram importantes referências como Lev Vygotsky, Edgar Morin, Paulo Freire dentre outros. Vygotsky (1991) propõe reflexões a respeito do papel do entorno social na formação humana, e o reflexo dessas relações nos processos de ensino e aprendizagem. Argumenta que o desenvolvimento intelectual que "dá origem às formas puramente humanas de inteligência prática e abstrata, acontece quando a fala e a atividade prática, então duas linhas completamente independentes de desenvolvimento, convergem" (VYGOTSKY, 1991, p.20), ou seja, formação do discurso e do fazer, do desenvolvimento intelectual baseado na prática, na ação individual embasada no coletivo, impactando na sua historicidade. Nesta mesma linha, verifica-se que Morin (2003) aborda a condição social do indivíduo, ser interdisciplinar por natureza, composto por sua natureza ao mesmo tempo física e cultural. Argumenta da necessidade de um pensamento complexo a respeito da realidade, já que somente esse tipo de pensamento pode 
exercer alguma mudança em vivências igualmente complexas, principalmente no que tange a Universidade, a qual deve se adaptar às necessidades da contemporaneidade e "realizar sua missão transecular de conservação, transmissão e enriquecimento de um patrimônio cultural, sem o que não passaríamos de máquinas de produção e consumo" (MORIN, 2003, p.82).

Observa-se então, a urgência em se tratar as ações interdisciplinares no corpo do ensino, principalmente no que refere ao ensino superior, questionando a respeito da especialização, da disciplinaridade e do especialismo que, como argumenta Fontoura (2011, p.88), podem se tornar barreiras para a compreensão do mundo complexo, pois "[...] a sabedoria do ser humano, a profundidade do conhecimento deverá estar aliada a sua abrangência”. Este mesmo raciocínio é observado na fala de Japiassu (1976), que argumenta que o termo interdisciplinaridade se refere aos empreendimentos que conseguem incorporar resultados de várias especialidades e disciplinas, assim como métodos, procedimentos e instrumentos, os quais são comparados, julgados e transformados. Por outro lado, a disciplinaridade pode se entendida como uma exploração de área específica de conhecimento, estabelecendo fronteiras e homogeneidade científica, o que difere da interdisciplinaridade, que "se caracteriza pela intensidade de trocas entre os especialistas e pelo grau de interação real das disciplinas, no interior de um projeto específico de pesquisa" (JAPIASSU, 1976, p.74). Piaget (1985) orienta que interdisciplinaridade possui como resultante uma possível transdisciplinaridade. Nesse ponto faz-se importante a busca de definições a respeito do que sejam os termos disciplinaridade, multidisciplinaridade, interdisciplinaridade e transdisciplinaridade. O termo multidisciplinaridade evoca "uma simples justaposição, num trabalho determinado dos recursos de várias disciplinas, sem implicar necessariamente em um trabalho de equipe e coordenado" (JAPIASSU, 1976, p.72). Em relação à transdisciplinaridade, pode-se dizer que se refere, como o próprio termo expressa, àquilo que está através e além das diversas disciplinas, na busca de uma unidade dos conhecimentos (NICOLESCU, 1999). Busca-se, na transdisciplinaridade, uma relação multidimensional entre os diversos níveis da realidade, articulando as partes com o todo, dissolvendo os discursos homogêneos entre a ciência e a cultura (SANTOS, 2005).

Dessa forma, importa analisar a premência dos procedimentos interdisciplinares no âmbito escolar, em particular nas instituições de ensino superior, pois conforme afirmam Jantsch \& Bianchetti:

O interdisciplinar está se estabelecendo, hoje, não porque os homens decidiram, mas sim pela pressão, pelas necessidades colocadas pela materialidade do momento histórico. A materialidade histórica exige a presença da ciência e da tecnologia em qualquer espaço de atuação e de possível colaboração da universidade, seja no sentido instrumental ou no sentido da criação. (Jantsch \& Bianchetti, 1995, p. 198)

A Universidade, portanto, se porta como lócus de trocas e construções intensas, caracterizadas pela própria natureza interdisciplinar, formando não só acadêmicos, mas antes, cidadãos que se habilitam a formar pensamentos sistêmicos e holísticos, capazes de conectar especializações em novas bases para as ciências, as artes e humanidades. 


\subsection{Design e interdisciplinaridade}

As considerações a respeito dos conceitos e desdobramentos da interdisciplinaridade e de seus resultados transdisciplinares evocam reflexões a respeito da formação do profissional de design, área do conhecimento interdisciplinar por natureza. De acordo com Correia (2003), por ser flexível e aberta a interpretações distintas, o design se porta como um espaço de diálogo e trocas, na qual atores diversos são arrolados, conhecimentos e especialidades se convergem, concorrendo para um projeto com características sistêmicas, sinérgicas e holísticas. Neste contexto, encontra-se o designer, construtor e transformador da sociedade, pois, como afirma Redig (2011), o termo "design social é um pleonasmo [...] não existe design que não seja social - para a sociedade. Se não for, não é design". Nesta mesma linha, Miyashiro (2011) discute a respeito do fazer do design gráfico e a necessária preocupação com os impactos desse fazer na sociedade, em um complexo cenário contemporâneo e a transformação da consciência em frente a essa complexidade.

A instituição de ensino de design que não se atenta em formar um sujeito com um perfil holístico e consciente de seu papel social, corre o risco de enviar para o mercado de trabalho um profissional que não está preparado para que seus conhecimentos, tanto teóricos quanto práticos, sejam aplicados no sentido de afetar os usuários do projeto de design, no que tange o bem-estar e as relações sociais (MARTINS \& CUNHA LIMA, 2007). Isso implica que, associada a uma estrutura curricular que contemple essa formação, um professor que se porte como sujeito transformador das relações, buscando construir um espaço de experimentação e reflexão constantes, ampliadas para além da sala de aula, no sentido de possibilitar o surgimento de projetos de design que possuam dimensões sincréticas.

\subsection{O Projeto Exposições Itinerantes}

O projeto Exposições Itinerantes - O Designer Gráfico e o Planejamento Visual de Espaços Culturais - corrobora com todas as ementas do módulo III do curso de Tecnólogo em Design Gráfico, pois desenvolve um projeto que engloba Sinalética e Design Corporativo, Acabamento e Design de Embalagens, Insumos Gráficos e Sistemas de Impressão, Pré-Impressão e fechamento de arquivos ao passo que todos esses conteúdos são abordados massivamente na produção e no planejamento de uma exposição itinerante. Nesse sentido, o projeto contou com uma série de estratégias para que as atividades práticas de cada uma das disciplinas contribuíssem com o TIG durante todo seu processo de planejamento, execução e apresentação.

Os objetivos deste projeto são buscar a integração teoria-prática mediante o exercício da observação e análise; desenvolver um processo de ensino-aprendizagem pautado na pesquisa e na prática do campo de atuação; trabalhar a relação entre os conteúdos; congregar talentos; fomentar a postura cooperativa em detrimento à competitiva; estimular finalidades comunicativas e de informação, trabalhar aplicabilidade, orçamentos, planejamento estratégico e apresentação. Trata-se de uma temática pertinente em empregabilidade e contemporânea, de extrema relevância para os alunos que, no mercado, poderão engajar-se pelo conhecimento de peças, formatos, orçamentos, substratos, impressões, acabamentos especiais, contatos e ambientação gráfico-artística ou gráfico-comercial.

Os modelos de exposições e espaços culturais corroboram com o novo cenário tecnológico do século XXI, influenciando os processos comunicacionais e visuais. 
Chelini (2012, p. 60) ensina as "tecnologias da informação [...] são aquelas que permitem a criação, administração e difusão da informação através de dispositivos e equipamentos de acesso, operação e armazenamento de dados." Afirma que o intento de toda exposição é criar uma experiência impar para o visitante, local impregnado de sentidos. O espaço exposicional é lócus de interação por natureza, característica inerente ao se conceber uma exposição (Cury \& Shibata, 2015). Outro ponto que deve ser levado em consideração é que os espaços exposicionais requerem um projeto de atratividade, pois, conforme argumenta Faustini (2012), são lugares tidos como tediosos para muitos públicos, principalmente os jovens. Cria-se, pois um campo promissor para a atividade do designer gráfico ao passo que seus conhecimentos percorrem desde o planejamento visual, à sinalética, produção gráfica, embalagem, ilustração digital, manipulação e tratamento de imagens, processos de editoração e inúmeras outras áreas do conhecimento, ações que se pautam pelo desenvolvimento de projetos eficazes de exposição, "cujo potencial e interação depende o bem-estar do visitante", de acordo com Cossio (2011, p. 98). A abordagem intenciona promover o aprendizado experiencial, desenvolvendo nos discentes a autonomia profissional, através de noções de financiamento de projetos, captação de recursos, bem como a valorização da cultura.

\subsection{Metodologia}

O projeto tomou com premissa básica a organização e o uso de ferramentas comunicacionais que possibilitassem a maior integração possivel entre os participantes, tanto docentes quanto discentes, nos processos de inicialização, planejamento, execução, controle e conclusão dos referidos projetos. Tais preocupações surgem da pouca cultura de projeto, principalmente no que tange á educação, como afirma Moura \& Barbosa (2007), "o panorama atual parece estar mais para uma 'cultura do improviso' [...] hábitos de bons planejamentos, gestão, controle, acompanhamento e avaliação são raros em nosso meio".

Primeiramente, reuniões entre os professores do Módulo possibilitaram o surgimento do tema Exposições Itinerantes, cuja abrangência contemplaria todas as disciplinas envolvidas, no sentido de planejamento das ações, atividades docentes, critérios de avaliação e modelo de apresentação dos trabalhos a serem desenvolvidos durante o semestre corrente. Tais reuniões iniciais permitiram o alinhamento dos Planos de Ensino com o escopo do tema proposto. Desse alinhamento, surgiu um Edital do TIG detalhado com todas as características, rotinas, ementas, além do cronograma e sistema de avaliação do referido projeto. Tal edital foi apresentado no primeiro dia de aula para os alunos, sendo disponibilizado para consulta e download no sistema aula da Instituição. Para a escrita do edital, utilizou-se um portal de escrita colaborativa, em que todos os docentes puderam contribuir com a escrita e a revisão, que contou também com referências a Lei de Direitos Autorais para coibir a incidência de plágio na produção dos textos ou no uso das imagens dos projetos desenvolvidos pelas equipes.

Outra estratégia comunicacional foi a criação de grupos de discussão em aplicativos de redes sociais, o que garantiu que o alinhamento dos discursos fosse feito diariamente ou semanalmente. Após a aula, os professores postavam nesse grupo suas práticas o que garantia que todos tivessem conhecimento do andamento dos conteúdos e como cada uma de suas disciplinas poderiam ser associadas. Dessa 
maneira, além da disciplina TIG as demais disciplinas se apropriaram dos discursos dos colegas, fomentando a associação dos conteúdos por parte dos discentes.

Para desenvolver um projeto completo de uma exposição itinerante, foram organizadas diversas visitas técnicas em museus e centros culturais de Belo Horizonte, bem como em exposições temporárias que ocorriam na Cidade. Durante as visitas, as equipes foram atendidas, na medida do possível, por curadores e organizadores técnicos das exposições, o que possibilitou o recolhimento de informações a respeito de custos de produção, materiais e insumos utilizados na montagem das exposições.

De acordo com o edital, cada equipe, formada por até 6 integrantes, escolheria um tema relacionado às diversas áreas das Ciências Naturais: Física, Química, Biologia e Astronomia; Ciências Históricas: Astrofísica, Biologia, Geologia e Paleontologia; Ciências das Artes: espetáculos de teatro, música e dança, lançamentos de livros, discos, vídeos e filmes; Ciências Humanas: Sociologia, Ciência política, Antropologia, História, Linguística, Pedagogia, Economia, Administração, Comunicação Social, Contabilidade, Geografia, Direito, Arqueologia, Psicologia, Relações Internacionais. Cada equipe deveria elaborar um projeto inovador que resultaria em ações e produtos, a saber: uma maquete, um kit de divulgação e um projeto de captação de recursos, que cumpriria, igualmente, o papel de memorial descritivo de todo processo desenvolvido. Serão detalhadas a seguir cada um desses produtos.

\subsubsection{A maquete}

O objetivo da maquete era simular os espaços exposicionais, o projeto de sinalética, apresentando materiais e dispositivos utilizados em todo o projeto do espaço da exposição. Em caso de um projeto complexo de múltiplos ambiente, optouse pela representação o espaço principal, ou o que possuir o maior número de variedades de recursos visuais elaborados pela equipe. Essa peça corroborou com os princípios da disciplina Insumos Gráficos e Sistemas de Impressão, pois trazia, em escala, uma vasta variedade de materiais e sistemas de impressão e produção, além da disciplina Design Corporativo e Sinalética, pois a maquete possibilitou fazer o ensaio da mobilidade e acessibilidade.

\subsubsection{O Kit de Divulgação / Patrocínio}

As equipes apresentaram um kit promocional a ser apresentado a possíveis patrocinadores. O kit deveria conter peças de divulgação (folders, postais e materiais gráficos impressos por sistemas digitais ou industriais), peça de interatividade física (objetos que remetessem à exposição, objetivando transportar o usuário diretamente ao espaço criado, pequenas obras de arte e até produtos de exploração sensorial), peça de interatividade digital, como aplicativos, sistemas de realidade ampliada, Q.R. code e quaisquer gadgets que promovessem a interatividade com o usuário. A funcionalidade do aplicativo não seria avaliada, mas a sua aplicação, interface e seu sistema visual deverão ser apresentados. Esse kit corrobora com as disciplinas PréImpressão e Fechamento de Arquivos, pois gera subsídios práticos para as teorias abordadas nelas, bem como para as disciplinas Acabamento e Design de Embalagens, essenciais para a produção de materiais gráficos com qualidade profissional. 


\subsubsection{Projeto de Captação / Patrocínio / Financiamento Coletivo}

O projeto descreveu todo o conceito, materiais, sistemas computadorizados e demais recursos para o funcionamento da proposta da equipe. Deveria apresentar os custos operacionais de criação, desenvolvimento e produção do espaço cultural criado durante a disciplina. Dessa forma, foi previsto como financiar / patrocinar a produção, bem como proporcionar ao aluno conhecimento para que consiga fundos para projetos próprios ou de seus futuros clientes. Essa prática vai ao encontro dos princípios da disciplina Insumos Gráficos e Sistemas de Impressão, no que diz respeito a orçamentos e contatos com diversos fornecedores, bem como com a própria disciplina TIG, objetivando a preparação do discente para lidar com inúmeras áreas do conhecimento envolvidas no desenvolvimento um projeto.

\subsection{A execução dos projetos de exposição}

Seguindo as diretrizes do cronograma sugerido pelo Edital do TIG, as equipes iniciaram a definição dos subtemas para as exposições. Foram realizadas diversas oficinas, aulas expositivas e prática a respeito do conceito de maquetaria e materiais, visitas aos locais escolhidos para as exposições, já que, apesar de se caracterizarem como itinerantes, as mesmas deveriam ser instaladas primeiramente em um local, com a possibilidade de se ajustar em quaisquer espaços disponíveis.

As oficinas ocorriam nos horários presenciais das aulas e, muitas vezes, aos finais de semana. É interessante citar que os alunos, na estrutura dos horários semanais de aulas, possuem um momento de estudos coletivos, ou seja, um horário semanal destinado para o desenvolvimento de atividades relacionadas ao TIG, o qual pode ser utilizado da maneira que o aluno determinar, no interior ou fora das dependências da Instituição de Ensino. O UNIBH conta com um Laboratório de Experimentações Gráficas - LEGRA - que conta com uma infraestrutura disponível aos alunos para a execução de seus projetos, composta com computadores, impressora 3D e maquinários diversos.

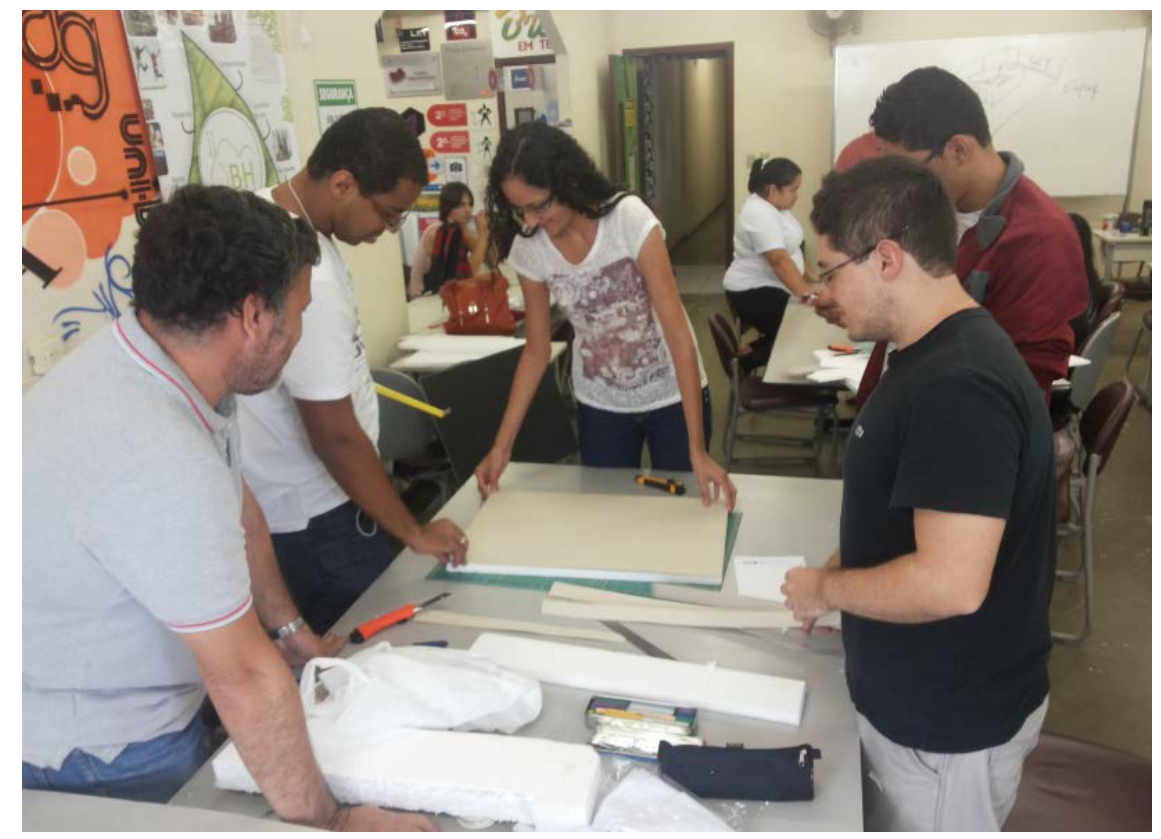

Figura 1 - Oficina de desenvolvimento de maquetes

Fonte: "Elaborado pelo autor, com base na pesquisa realizada". 


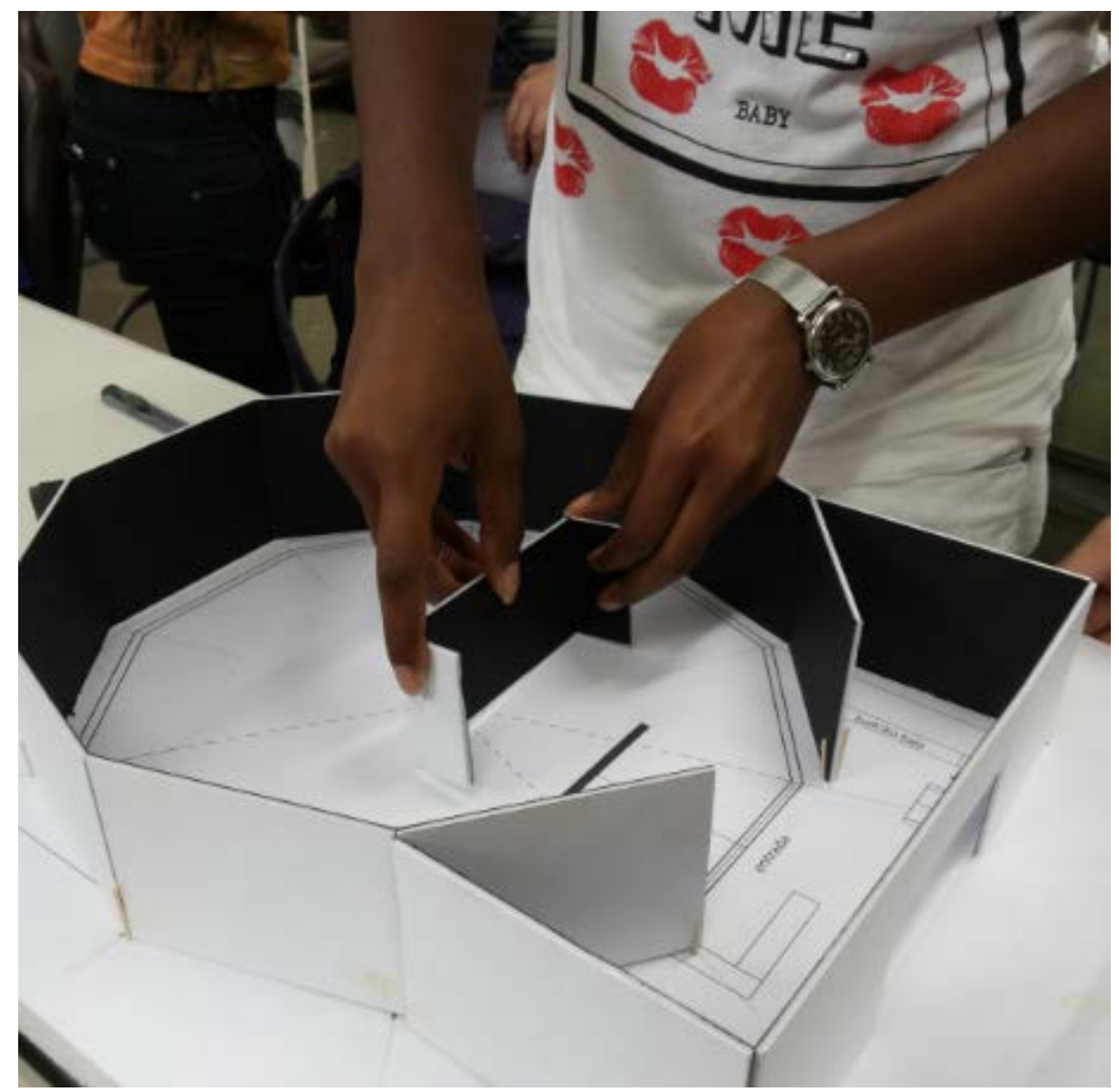

Figura 2 - Detalhe do desenvolvimento de maquetes

Fonte: "Elaborado pelo autor, com base na pesquisa realizada".

\subsection{A Mostra no Circuito Acadêmico}

Ao final de cada semestre, ocorre o Circuito Acadêmico, realizado nas dependências do UNIBH, oportunidade na qual as equipes apresentam os resultados finais dos projetos. Para tal, foi concedido o stand com $27 \mathrm{~m}^{2}$ que comportou todos os projetos simultaneamente. As equipes apresentaram o material impresso (maquete, kit de prospecção e banner), e áudio visual (apresentação digital e tour virtual), tanto com os avaliadores dos projetos quanto com os visitantes, os quais puderam ver, ler e tocar nos projetos. $\mathrm{O}$ formato inovador garantiu maior visibilidade para esses projetos bem como para os discentes que puderam fazer contatos profissionais durante 0 evento. 


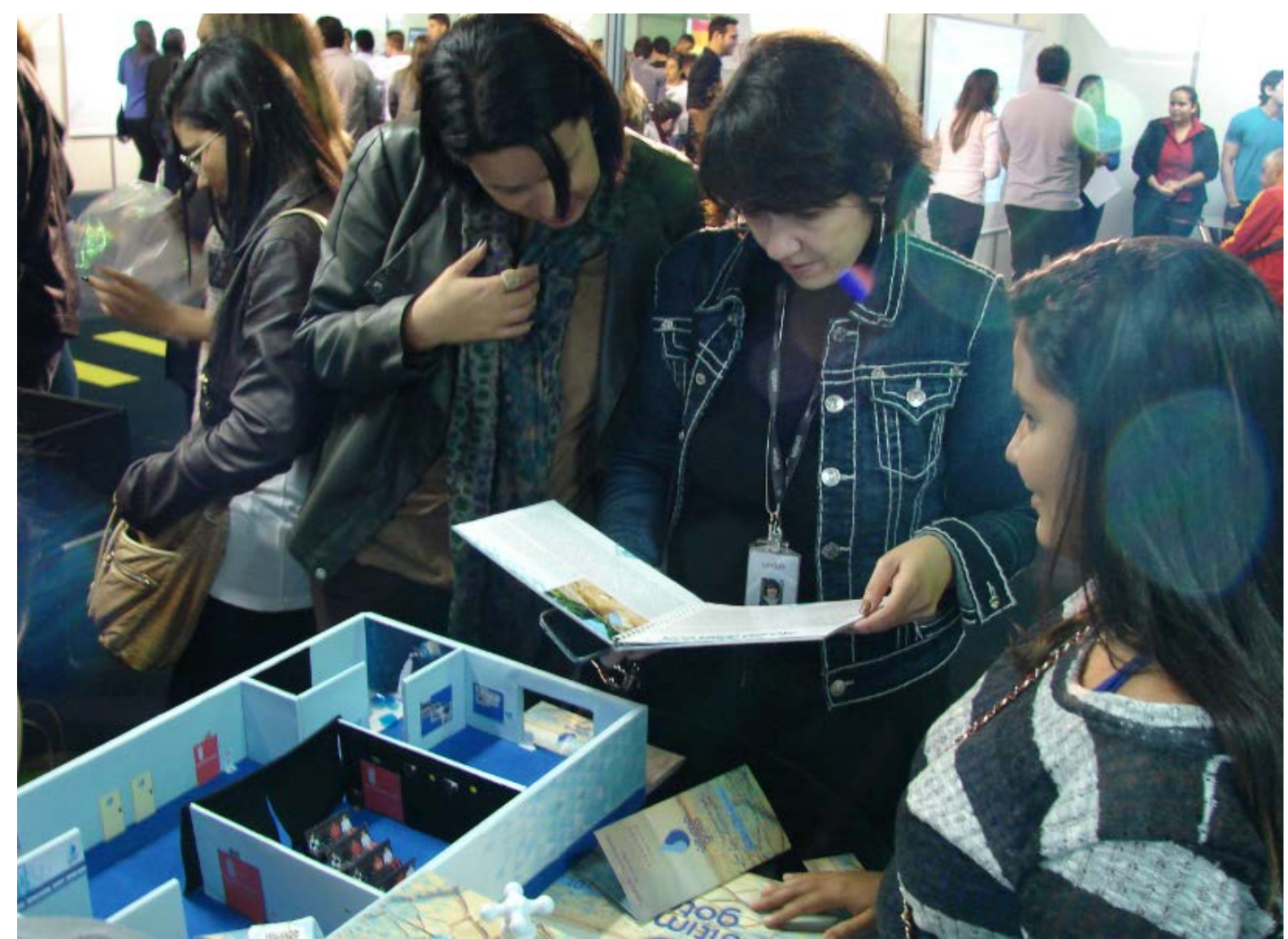

Figura 3 - Exposição dos projetos no Circuito Acadêmico, ocorrida em junho de 2015

Fonte: "Elaborado pelo autor, com base na pesquisa realizada".

\section{CONCLUSÃO}

O Projeto Exposições Itinerantes possibilitou aos alunos vivenciar a experiência de produção de projetos com equipes híbridas, bem como a pesquisa e a inovação. Foi dada a oportunidade de ampliar as possibilidades de atuação do profissional em Design Gráfico, ao passo em que sua formação propõe projetos inovadores e contemporâneos. O planejamento, da escrita à execução, o projeto integrado forneceu aos alunos arcabouços teóricos e práticos essenciais para o exercício de sua profissão, de maneira dinâmica e inovadora, se apresentando como uma experiência efetiva da interdisciplinaridade.

Ao receberem apoio e ao perceberem que a equipe docente estava engajada eles seguiram o exemplo. Percebeu-se que o discurso era compartilhado entre eles pelas redes sociais e constantemente eles se referiam ao TIG como o mais integrado que já haviam vivenciado. A formação do profissional em comunicação necessita estar ligada diretamente à formação humana, sobretudo em questões culturais. Essa prática conseguiu incentivar os alunos a consumirem, conhecerem e planejarem espaços culturais mais adaptados à sociedade, no que diz respeito a integração, acessibilidade e sustentabilidade.

Os projetos desenvolvidos de forma interdisciplinar se mostram cada vez mais como um caminho eficaz nos processos de ensino/aprendizagem, garantindo a construção do conhecimento e a possibilidade de resultados transdisciplinares, pois vão além da simples transmissão de conteúdos. No que se refere ao Projeto Exposições Itinerantes, os resultados obtidos se expandiram para além do horizonte definido pelo escopo do planejamento, já que muitos deles receberam propostas de realização efetiva. Entretanto, o mais importante foi a tomada de consciência, tanto 
dos docentes quanto dos discentes envolvidos no processo, da importância do planejamento sob o viés da interdisciplinaridade, que não se apresenta apenas com uma área do conhecimento, mas antes uma filosofia e estado de espírito.

\section{REFERÊNCIAS}

CHELINI, Maria Julia Estefânia. NOVAS TECNOLOGIAS PARA... NOVAS (?)

EXPOGRAFIAS. Revista Museologia e Interdisciplinaridade - UNB, Brasília. Vol. I, no2, jul/dez de 2012.

CORREIA, Rita Isabel Pimenta Peseiro dos Reis. A Interacção do Design Industrial com a Ciência e a Tecnologia: a abordagem interdisciplinar, 2003. (dissertação para obtenção de mestre em desenho industrial). Faculdade de Engenharia da Universidade do Porto. Escola Superior de Artes e Design de Matosinhos. Portugal.

COSSIO, Gustavo. Design de Exposição de Design: três estudos sobre critérios projetuais para comunicação com o público. 2011. 204 f. (dissertação para obtenção de título de mestre em design). Universidade Federal do Rio Grande do Sul, Faculdade de Arquitetura

CURY, Marilia Xavier; SHIBATA, Lucia. Desenvolvimento Conceitual da Expografia: estudo de caso com adoção da pesquisa-ação participativa. XVI Encontro Nacional de Pesquisa em Ciência da Informação, 2015. João Pessoa, PB.

FAUSTINI, Marcus. A Relação entre Museus e Jovens. In Reprograme: comunicação, branding, cultura numa nova era de museus. MENDES, Luis Marcelo (org). Rio de Janeiro: Ímã, 2012.

FONTOURA, Antônio. M. A interdisciplinaridade e o ensino do design. Projética Revista Científica de Design, Universidade Estadual de Londrina, v.2, no. 2, Dezembro 2011

JANTSCH, Ari Paulo; BIANCHETTI, Lucídio. Universidade e Interdisciplinaridade in Interdisciplinaridade: para além da filosofia do sujeito. JANTSCH, A. P; BIANCHETTI, L. (orgs.). Petrópolis, Rj: Vozes, 1995

JAPIASSU, Hilton. Interdisciplinaridade e a Patologia do Saber. Rio de Janeiro, Imago, 1976.

MARTINS, Bianca; CUNHA LIMA, Edna Lúcia. Uma discussão sobre o papel social do designer gráfico brasileiro: trajetória, formação acadêmica e prática profissional. 70 Congresso Brasileiro de Pesquisa e Desenvolvimento em Design. Paraná: 2006.

MIYASHIRO, Rafael Tadashi. Com design, além do design: os dois lados de um design gráfico com preocupações sociais. In BRAGA, Marcos da Costa. O Papel Social do Design Gráfico. 1. ed. São Paulo: SENAC-SP, 2011. v. 1. 192p .

MORIN, Edgar. A cabeça bem-feita: Repensar a reforma, reformar o pensamento. Rio de Janeiro: Bertrand Brasil, 2003.

MOURA, Dácio Guimarães; BARBOSA, Eduardo Fernandes - Trabalhando com Projetos: Planejamento e Gestão de Projetos Educacionais, 2a ed. Petrópolis - RJ: Vozes,, 2007. $246 p$ 
NICOLESCU, Basarab. Um novo tipo de conhecimento: transdisciplinaridade. 10 Encontro Catalisador do CETRANS - Escola do Futuro - USP, Itatiba, São Paulo - Brasil: abril de 1999.

PIAGET, Jean. Psicologia e Pedagogia. Editora Forense Universitária. RJ. Tradução de: Dirceu Accioly Lindoso e Rosa Maria Ribeiro da Silva - Sétima impressão - 1985

RANCIÈRE, Jacques. A partilha do Sensível: estética e política. São Paulo: EXO experimental org.: Ed. 34, 2005. 72 p.

REDIG, Joaquim. Design: responsabilidade social no horário do expediente. In BRAGA, Marcos da Costa. O Papel Social do Design Gráfico. 1. ed. São Paulo: SENAC-SP, 2011. v. 1. $192 p$.

SANTOS, Akiko. Complexidade e transdisciplinaridade em educação: cinco princípios para resgatar o elo perdido. Revista Brasileira de Educação v. 13 n. 37 jan./abr. 2008.

UNIBH, Centro Universitário de Belo Horizonte. Edital do Trabalho Interdisciplinar de Graduação: Módulo III - Design Gráfico. 2015. Belo Horizonte, MG. 